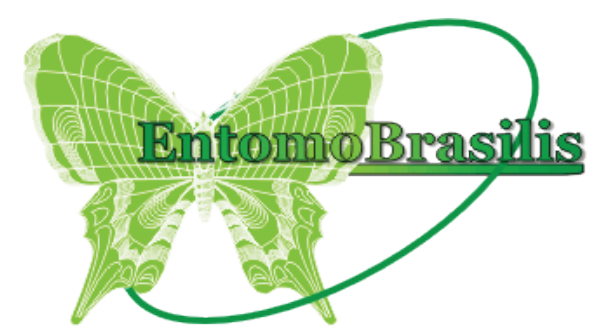

\title{
Novos Insetos Sugadores (Hemiptera) Atacando Eucalyptus cloeziana (Myrtaceae) em Minas Gerais, Brasil
}

\author{
Claubert Wagner Guimarães de Menezes ${ }^{1}$, Marcus Alvarenga Soares ${ }^{\circledR}{ }^{\bowtie}$, Sebastião Lourenço de Assis Júnior ${ }^{1}$, \\ Arley José Fonseca ${ }^{1}$, Evaldo Martins Pires² \& José Barbosa dos Santos ${ }^{1}$
}

\begin{abstract}
1. Universidade Federal dos Vales do Jequitinhonha e Mucuri, e-mail: claubertmenezes@yahoo.com.br, marcusasoares@yahoo.com.br (Autor para correspondência ${ }^{\bowtie}$ ), assisjr ento@yahoo.com.br, arley.agro@yahoo.com.br, ibarbosasantos@yahoo.com.br. 2. Universidade Federal do Mato Grosso,
\end{abstract} e-mail: evaldo@ufmt.br.

\section{EntomoBrasilis 5 (3): 246-248 (2012)}

Resumo. A migração de pragas de plantas nativas para a eucaliptocultura pode causar perdas significativas em sua produção. Foi relatada a ocorrência das cigarrinhas Aethalion reticulatum Linnaeus (Hemiptera: Aethalionidae) e Membracis lunata Fabricius (Hemiptera: Membracidae) em Eucalyptus cloeziana F. Muell. (Myrtaceae) no município de Couto de Magalhães de Minas, em Minas Gerais, Brasil. As espécies foram observadas em plantas de eucalipto em fase vegetativa no campo. A ocorrência desses insetos atacando o eucalipto indica sua migração de plantas frutíferas para o novo hospedeiro, não sendo recomendável a instalação de florestas de eucalipto próximas a áreas com fruticultura.

Palavras-Chave: Cigarrinhas; Fitófagos; Soluções Açucaradas.

\section{New sucking insects (Hemiptera) attacking Eucalyptus cloeziana (Myrtaceae) in Minas Gerais, Brazil}

Abstract. The migration of pests of plants native to eucalyptus can cause significant losses in production. Been reported to occur of the leafhopper Aethalion reticulatum Linnaeus (Hemiptera: Aethalionidae) and Membracis lunata Fabricius (Hemiptera: Membracidae) in Eucalyptus cloeziana F. Muell. (Myrtaceae) in the municipality of Couto de Magalhães de Minas, Minas Gerais, Brazil. The species were observed in eucalyptus plants in the vegetative stage in the field. The occurrence of these insects attacking eucalyptus indicates their migration from fruit trees to the new host and is not recommended to install eucalyptus forests near areas with fruit trees.

Keywords: Honeydew; Leafhopper; Phytophagous.

$\mathbf{N}$ Brasil, aproximadamente cinco milhões de hectares são cultivados com a cultura do eucalipto. Essa planta apresenta rápido crescimento e favorável adaptação às condições climáticas do país (ABRAF 2011). Devido ao seu ecossistema homogêneo, oferta de alimento e diminuição da diversidade de inimigos naturais, essa cultura está vulnerável ao ataque de pragas nativas e exóticas, que acarretam perdas em sua produção (SANTOS et al. 2008).

Plantações de eucaliptos têm enfrentado ataques de pragas exóticas, tais como o Glycaspis brimblecombei (Moore) (Hemiptera: Psyllidae) (psilídeo de concha), identificado no país em 2003, Leptocybe invasa Fisher \& LaSalle (Hymenoptera: Eulophidae) (vespa-de-galha) identificada no final de 2007 e o Thaumastocoris peregrinus Carpintero \& Dellapé (Hemiptera: Thaumastocoridae) (percevejo bronzeado) observado em 2008 (Kim et al. 2008; NADEL et al. 2010; Silva et al. 2010). Além disso, a migração de pragas de plantas nativas, que passam atacar espécies de eucalipto, é um problema frequente para a eucaliptocultura no Brasil. O objetivo deste trabalho foi relatar o ataque de insetos sugadores (Hemiptera) em plantas de Eucalyptus cloeziana F. Muell. (Myrtaceae) no município de Couto de Magalhães de Minas, estado de Minas Gerais, Brasil.

As plantas de E. cloeziana observadas pertenciam a um povoamento florestal localizado no município de Couto de Magalhães de Minas, no estado de Minas Gerais, nas coordenadas $18^{\circ} 04^{\prime} 15^{\prime \prime S}$ e $43^{\circ} 28^{\prime} 15^{\prime \prime} \mathrm{O}$. O povoamento, com um ano de idade, apresentava em média 2,0 $\mathrm{m}$ de altura. Essas plantas encontravam-se em fase vegetativa e com dossel visualmente uniforme. Observou-se a ocorrência de imaturos e adultos de Aethalion reticulatum Linnaeus (Hemiptera: Aethalionidae) e Membracis lunata Fabricius (Hemiptera: Membracidae) entre os meses de março e julho do ano de 2011, sugando a seiva das plantas, em suas folhas e galhos mais novos.

A espécie $A$. reticulatum é conhecida popularmente como cigarrinha do pedúnculo ou das fruteiras e apresentam cor marrom ferrugíneo, medindo cerca de $10 \mathrm{~mm}$ de comprimento, e com nervuras das asas salientes e esverdeadas (Figuras 1A e B). As fêmeas colocam uma massa de aproximadamente 100 ovos em galhos ou pedúnculos das plantas, envoltos por uma substância de cor parda ou acinzentada, o que pode confundir predadores. O período de incubação dos ovos é em torno de 30 dias, e as fêmeas apresentam a característica de proteger a postura até a eclosão (VIEIRA et al. 2007), fato observado em campo (Figura 1B). As ninfas apresentam o corpo de coloração cinza com estrias avermelhadas, são sugadoras de seiva, possuem hábito gregário e permanecem nesse estádio até 45 dias (VIEIRA et al. 2007). Seu ciclo de vida se completa em 110 dias, com três gerações ao ano. Ninfas e adultos apresentam movimento rápido e lateral, sendo característico dessa espécie, e os adultos apresentam longevidade de até dois meses (VIEIRA et al. 2007). Este Aethalionidae tinha sua ocorrência relacionada apenas com plantas frutíferas no país (GALlo et al. 2002). Já M. lunata são conhecidos como soldadinhos, sendo uma cigarrinha sugadora de seiva comum em plantas frutíferas, que apresenta um pronoto foliáceo, arredondado, preto e branco, com três faixas em forma 
de lua (SAKAKibara \& EvangElista 2010). As fêmeas colocam seus ovos em superfícies de ramos e galhos, e os protegem durante a fase de incubação. Esses ovos são cobertos por uma secreção pegajosa e esbranquiçada. As ninfas apresentam processos espinhosos no dorso, pretos (Figuras 1C e D). Possuem hábito gregário nas plantas e se protegem rapidamente deslocando-se nos galhos ou voando, quando molestados.

Ao se alimentarem da seiva, essas cigarrinhas excretam via anal um líquido composto por diversos açúcares como a glicose, frutose e sacarose, e mais aminoácidos livres, lipídios, amido, vitamina B e minerais (honeydew). A composição desse líquido pode variar de acordo com a planta hospedeira, sua idade, a parte da planta onde o inseto se alimenta e o tempo de alimentação (FowLER et al. 1991). O honeydew serve de substrato energético para diferentes espécies de formigas, onde essas desempenham o papel de protetoras das cigarrinhas contra inimigos naturais, formando assim uma relação benéfica entre ambas (Morales 2000) (Figura 1A). Algumas espécies de formigas ainda estimulam o abdômen desses insetos com suas antenas e tarso a fim de obterem gotículas de honeydew para se alimentarem (RANDo \& Lima 2010).

A ocorrência desses insetos em povoamentos de eucaliptos é um indicativo de maior atenção quanto à população de pragas presentes nesse ecossistema, pois, altas infestações dessas cigarrinhas podem levar a depleção de nutrientes dessas plantas, irregularidades no crescimento e consequente desuniformidade de plantio. Além disso, grandes quantidades de honeydew podem propiciar o desenvolvimento de fungos formadores de fumagina, reduzindo a taxa fotossintética da planta. Picadas sucessivas e a extração da seiva podem também causar deformações e encarquilhamento de folhas, morte de brotos terminais, perda de dominância apical e superbrotamento de galhos laterais. Esse trabalho registra pela primeira vez a ocorrência das cigarrinhas $A$. reticulatum e $M$. lunata no hospedeiro $E$. cloeziana, importante espécie florestal e de grande interesse econômico no país. A ocorrência desses insetos atacando o eucalipto indica sua migração das plantas frutíferas para o novo hospedeiro, não sendo recomendável a instalação de florestas de eucalipto da espécie E. cloeziana próximas a áreas com fruticultura.

\section{REFERÊNCIAS}

ABRAF - Associação Brasileira de Produtores de Florestas Plantadas, 2010. Disponível em: <http://www.abraflor.org.br>. Acesso em 12 de out. 2011.

Fowler, H.G., 1991. Ecologia nutricional de formigas p. 123-131. In: Panizzi, A.R. \& J.R.P. Parra. (Eds.). Ecologia nutricional de insetos e suas implicações no manejo de pragas. Manole, São Paulo, 359 p.

Gallo, D., O. Nakano, S. Silveira Neto, R.P.L. Carvalho, G.C. Batista, E. Berti Filho, J.R.P. Parra, R.A. Zucchi, S.B. Alves, J.D. Vendramim, L.C. Marchini, J.R.S. Lopes \& C. Omoto, 2002. Manual de entomologia agrícola. FEALQ, Piracicaba, $920 \mathrm{p}$.

Kim, J.K., Z. Mendel, A. Protasov, D. Blumberg \& J. La Salle, 2008. Taxonomy, biology, and efficacy of two Australian parasitoids of the eucalyptus gall wasp, Leptocybe invasa Fisher \& La Salle (Hymenoptera: Eulophidae: Tetrastichinae). Zootaxa, 1910: 1-20.

Morales, M.A., 200o. Mechanisms and density dependence of benefit in an ant-membracid mutualism. Ecology, 81: 482-
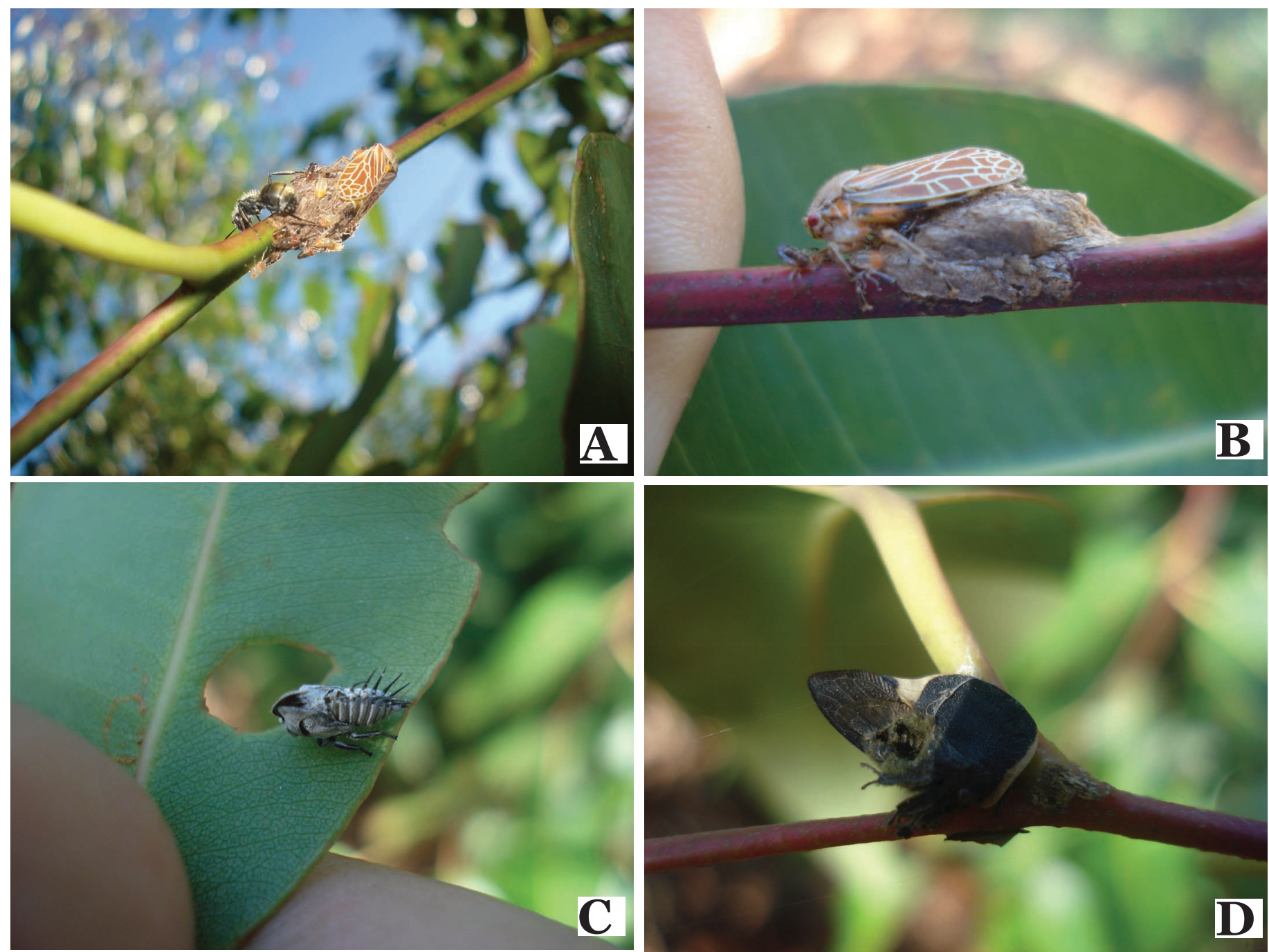

Figura 1. Aethalion reticulatum Linnaeus (Hemiptera: Aethalionidae) (A e B) e Membracis lunata Fabricius (Hemiptera: Membracidae) (C e D) atacando Eucalyptus cloeziana F. Muell (Myrtaceae) no município de Couto de Magalhães de Minas, estado de Minas Gerais, Brasil. Foto: S.L. de Assis-Júnior. 
489.

Nadel, R.L., B. Slippers, M.C. Scholes, S.A. Lawson, A.E. Noack, C.F. Wilcken, J.P. Bouvet \& M.J. Wingfild, 2010. DNA barcoding reveals source and patterns of Thaumastocoris peregrinus invasions in South Africa and South America. Biological Invasions, 12: 1067-1077.

Rando, J.S.S. \& C.B. LIMA, 2010. Detecção de Aethalion reticulatum (L., 1767) (Hemiptera: Aethalionidae) em alfavaca-cravo (Ocimum gratissimum L.) e observações sobre sua ocorrência. Revista Brasileira de Plantas Medicinais, 1: 239-242.

Sakakibara, A.M. \& O. Evangelista, 2010. Membracis foliata (Linnaeus) (Hemiptera: Membracidae: Membracinae) and allied species: an effort towards their correct determination. Journal of Natural History, 44: 2131-2148.

Santos, G.P., J.C. Zanuncio, T.V. Zanuncio \& E.M. Pires, 2008. Pragas do Eucalipto. Informe Agropecuário, 29: 43-64.
Silva, J.O., N.K. Oliveira, K.J. Santos, M.M. Espirito-Santo, F.S. Neves \& M.L. Faria, 2010. Effects of landscape structure and Eucalyptus genotype on the abundance and biological control of Glycaspis brimblecombei Moore (Hemiptera: Psyllidae). Neotropical Entomology, 39: 91-96.

Vieira, C.U., C.M. Rodovalho, L.O. Almeida, A.C.S. Siquieroli \& A.M. Bonetti, 2007. Interação entre Trigona spinipes Fabricius, 1793 (Hymenoptera: Apidade) e Aethalionidae reticulatum Linnaeus, 1767 (Hemiptera: Aethalionidae) em Mangifera indica (Anacardiaceae). Bioscience Journal, 23: 10-13.

\section{Recebido em: 01/11/2011}

Aceito em: 15/o5/2012

Como citar este artigo:

Menezes, C.W.G., M.A. Soares, S.L. Assis Júnior, A.J. Fonseca, E.M. Pires \& J.B. Santos, 2012. Novos Insetos Sugadores (Hemiptera) Atacando Eucalyptus cloeziana (Myrtaceae) em Minas Gerais, Brasil. EntomoBrasilis, 5(3): 246-248.

Acessível em: http://www.periodico.ebras.bio.br/ojs/index.php/ebras/article/view/211

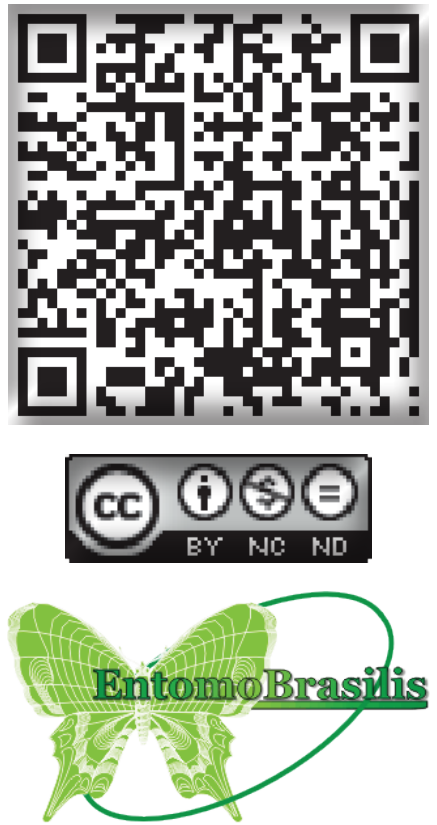

